\title{
Radiocarbon in Polar Ice: The Mechanism by Which Radiocarbon is Preserved in Firn Grains
}

\author{
A. V. Nesterenok and V. O. Naidenov \\ Ioffe Physical-Technical Institute, Russian Academy of Sciences, \\ Politekhnicheskaya ul. 26, St. Petersburg, 194021 Russia \\ Received October 14, 2009; in final form, April 21, 2010
}

\begin{abstract}
This work is devoted to the problem of localizing the ${ }^{14} \mathrm{C}$ cosmogenic radionuclide in a firn layer covering glaciers. The data on ${ }^{14} \mathrm{C}$ in ice samples from the GISP2 ice core drilled on a Greenland ice dome (Summit) are analyzed. It has been indicated that experimental values of the ${ }^{14} \mathrm{C}$ concentration are systematically smaller than theoretically calculated values, which indicates that firn grains partially lose ${ }^{14} \mathrm{C}$. Diffusion of cosmogenic ${ }^{14} \mathrm{C}$ in firn grains and hydration of ${ }^{14} \mathrm{CO}_{2}$ in a disordered ice layer, which is formed on a firn grain surface and at the boundary between ice monocrystals, are considered. It has been indicated that these processes are among the main ones responsible for the level of radiocarbon concentration in firn and ice samples.
\end{abstract}

DOI: $10.1134 / \mathrm{S} 0016793211020113$

\section{INTRODUCTION}

Different sources (instrumental observations, historical documents, bottom sediments, sedimentary rocks, tree rings, and ice cores) give information about geophysical conditions on our planet in the past. However, data on ice cores are the most exact and detailed archive of the past climatic changes. Ice cores have a high dating accuracy and resolution and cover a time interval of several hundred thousand years; therefore, they form the basis for interpreting the data of other natural archives. A complex analysis of different indicators in ice cores makes it possible to reconstruct changes in any environmental parameter. Cosmogenic nuclides, which are produced in the atmosphere and lithosphere during nuclear reactions caused by cosmic radiation, are among such indicators. Data on the concentration of cosmogenic nuclides in natural archives give information about changes in the level of solar and geomagnetic activity and terrestrial climate in the past.

The present work considers the production and deposition of the ${ }^{14} \mathrm{C}$ cosmogenic nuclide in polar ice. The reaction of thermal neutron capture by nitrogen nuclei

$$
{ }^{14} \mathrm{~N}+n \rightarrow{ }^{14} \mathrm{C}+p
$$

is the main channel of the ${ }^{14} \mathrm{C}$ production in the atmosphere.

After formation, ${ }^{14} \mathrm{C}$ oxidizes to $\mathrm{CO}_{2}$ and subsequently participates in environmental exchange processes until it goes to a "natural archive": tree rings, peat layers, lacustrine sediments, etc. (Dergachev et al., 2006). Data on ${ }^{14} \mathrm{C}$ in natural archives such as tree rings together with data on ${ }^{10} \mathrm{Be}$ and ${ }^{36} \mathrm{Cl}$ in polar ice represent chronicles of past variations in climatic and geophysical conditions on the planet. The ${ }^{14} \mathrm{C}$ cosmogenic nuclide in polar ice has been studied to a lesser extent. This is partly related to the fact that deposition of ${ }^{14} \mathrm{C}$ in polar ice is a complex process with numerous influencing variables, as a result of which it is difficult to use this radionuclide as an indicator. Radiocarbon precipitates in polar ice together with atmospheric air and is "in situ" produced in ice during reactions caused by secondary cosmic radiation. Atmospheric radiocarbon precipitates during the last stage of firn transformation into ice, when air pores close up and air bubbles form.

The ${ }^{14} \mathrm{C}$ nuclide is produced by cosmic radiation mainly in surface firn layers with thickness of several meters. Spallation of oxygen nuclei by neutrons of the cosmic ray nuclear-active component mainly contribute to radiocarbon production in ice:

$$
{ }^{16} \mathrm{O}+n \rightarrow{ }^{14} \mathrm{C}+X
$$

where $X$ are reaction products. The contribution of thermal neutrons capture by nitrogen nuclei is negligible, since the nitrogen content is small in ice. Numerical simulation of the ${ }^{14} \mathrm{C}$ production by the cosmic ray nuclear-active component was performed in (Masarik and Reedy, 1995) and in later works of these researchers. In addition, the production rate value was determined experimentally based on the data on the radiocarbon concentration in rocks with a known age (Jull et al., 1994). Latitudinal and altitudinal dependences of the neutron monitor count rate are used to recalculate the radionuclide production rate for a specified altitude and geomagnetic latitude (Desilets and Zreda, 2003). 
At depths greater than the penetration depth of the cosmic ray nuclear-active component, the reactions caused by the muon component (namely, the reactions of capture of slow negative muons by oxygen atoms)

$$
{ }^{16} \mathrm{O}+\mu^{-} \rightarrow{ }^{14} \mathrm{C}+n+p+v_{\mu}
$$

and high-energy muons

$$
{ }^{16} \mathrm{O}+\mu^{ \pm} \rightarrow{ }^{14} \mathrm{C}+\mu^{ \pm}+X .
$$

are the main channel of ${ }^{14} \mathrm{C}$ production. Production of radiocarbon by the muon component takes place at depths of up to 100 m.w.e. (meters of water equivalent; 1 m.w.e. $=100 \mathrm{~g} \mathrm{~cm}^{-2}$ ) and more (Nesterenok and Naidenov, 2010).

A newly formed "in situ" ${ }^{14} \mathrm{C}$ atom has about $1 \mathrm{MeV}$ energy. An atom of ${ }^{14} \mathrm{C}$ spends its energy on collisions with atoms and molecules in the environment. When the atom energy reaches $\sim 10 \mathrm{eV}$, stable chemical compounds can be formed in collisions with water molecules. Based on available data on ${ }^{14} \mathrm{C}$ in polar ice, we can conclude that $\mathrm{CO}$ and $\mathrm{CO}_{2}$ are the main products of "hot" ${ }^{14} \mathrm{C}$ chemistry in ice. However, more complex chemical compounds (methane $\left(\mathrm{CH}_{4}\right)$, formaldehyde $\left(\mathrm{CH}_{2} \mathrm{O}\right)$, etc.) can also be formed (Roessler, 1991).

Based on the experimental data on ${ }^{14} \mathrm{C}$ in the GISP2 Greenland ice core samples, Lal et al. (2005) concluded that the degree of ${ }^{14} \mathrm{C}$ preservation in ice crystal lattices is high. However, a low ${ }^{14} \mathrm{C}$ level in samples from Antarctic ice cores indicates that firn grains lost ${ }^{14} \mathrm{C}$ during ice formation (Smith et al., 2000; Lal et al., 2001). During the stage of firn transformation into ice, ice grains lose ${ }^{14} \mathrm{C}$ : carbon oxide molecules diffuse into firn air pores and subsequently leak into the atmosphere.

In this study we analyze the data on ${ }^{14} \mathrm{C}$ in the GISP2 Greenland core samples published in (Lal et al., 1997, 2000, 2005). The work considers the problem of ${ }^{14} \mathrm{CO}$ and ${ }^{14} \mathrm{CO}_{2}$ molecule mobility in ice crystal lattices. We also consider the problem of ${ }^{14} \mathrm{CO}_{2}$ hydration in a disordered ice layer, which forms on ice crystal surfaces and at the boundary between ice monocrystals. We for the first time numerically estimate the characteristic time of the aforementioned processes as applied to the considered problem. The aim of the work is to indicate that it is necessary to understand these processes in order to more accurately interpret experimental data.

\section{EXPERIMENTAL DATA}

Table 1 presents experimental data on ${ }^{14} \mathrm{C}$ in the considered ice samples. Column 1 of Table 1 presents the sample code; column 2, the sampling depth (Lal et al., 1997, 2000); column 3, the age of the ice according to (Meese et al., 1994) (the age is counted from 1950). Column 4 presents the average sedimentation (ice accumulation) rate during a period corresponding to the sample age; this quantity is measured in equivalent ice centimeters per year (Alley, 2000). The experimental method for determining the ${ }^{14} \mathrm{C}$ concentration includes melting of ice samples. The effectiveness of ${ }^{14} \mathrm{C}$ extraction using this method is, as a rule, higher than $80 \%$ (Lal et al., 2000). The data on the concentration for the first three samples and the tenth sample are taken from (Lal et al., 1997); for the remaining nine samples, from (Lal et al., 2000) (see column 5 of Table 1 ). The ${ }^{14} \mathrm{C}$ concentration was measured separately for the $\mathrm{CO}$ and $\mathrm{CO}_{2}$ components of the extracted gases. The contribution of ${ }^{14} \mathrm{CO}$ to the total ${ }^{14} \mathrm{C}$ concentration varies from sample to sample and is about $30 \%$ on average. The total amount of ${ }^{14} \mathrm{C}$ in ice samples is the sum of ${ }^{14} \mathrm{C}$ produced in situ and atmospheric ${ }^{14} \mathrm{C}$ captured together with air bubbles during ice formation. According to (Lal et al., 2000), the contribution of carbonate dust to the total ${ }^{14} \mathrm{C}$ concentration is negligible. In this work, the amount of atmospheric radiocarbon was estimated based on the air volume in an ice sample (see column 6 of Table 1 (Lal et al., 1997, 2000)), fraction of $\mathrm{CO}_{2}$, and amount of ${ }^{14} \mathrm{C}$ in the atmosphere during a period corresponding to the air age (Petit et al., 1999; McCracken et al., 2005). The standard ${ }^{14} \mathrm{C} /{ }^{12} \mathrm{C}$ ratio in the atmosphere was set equal to $1.5 \times 10^{-12}$ (Marley et al., 2009). Column 7 of Table 1 presents the concentration of atmospheric ${ }^{14} \mathrm{CO}_{2}$ (in this case, the concentration of atmospheric ${ }^{14} \mathrm{CO}$ can be neglected).

Column 8 of Table 1 presents the concentration of ${ }^{14} \mathrm{C}$ produced by secondary cosmic radiation when ice samples were stored on the Earth's surface. This amount of ${ }^{14} \mathrm{C}$ was determined based on the data presented in (Lal et al., 2000). It was taken into account that Lal et al. (2000) used an underestimated value for the ${ }^{14} \mathrm{C}$ production rate by the nuclear-active component of cosmic rays (see the remarks in (Van der Kemp et al., 2002)).

\section{CONCENTRATION OF ${ }^{14} \mathrm{C}$ IN ICE SAMPLES}

On the assumption that radiocarbon is not lost during ice formation, the concentration of ${ }^{14} \mathrm{C}$ in situ in ice at depth $h$ is defined by the following expression (Nesterenok and Naidenov, 2010):

$$
n_{\text {theor }}=\frac{Q_{h}+Q_{\mu^{-}}+Q_{\mu f}}{s \rho} e^{-\lambda t} \quad[\mathrm{at} / \mathrm{g}],
$$

where $t$ is the age of ice at depth $h ; s$ is the average ice accumulation rate during a period of radionuclide production (in equivalent ice centimeters per year); $\rho$ is ice density; $\lambda$ is the decay constant; $Q_{h}, Q_{\mu}$, and $Q_{\mu f}$ 


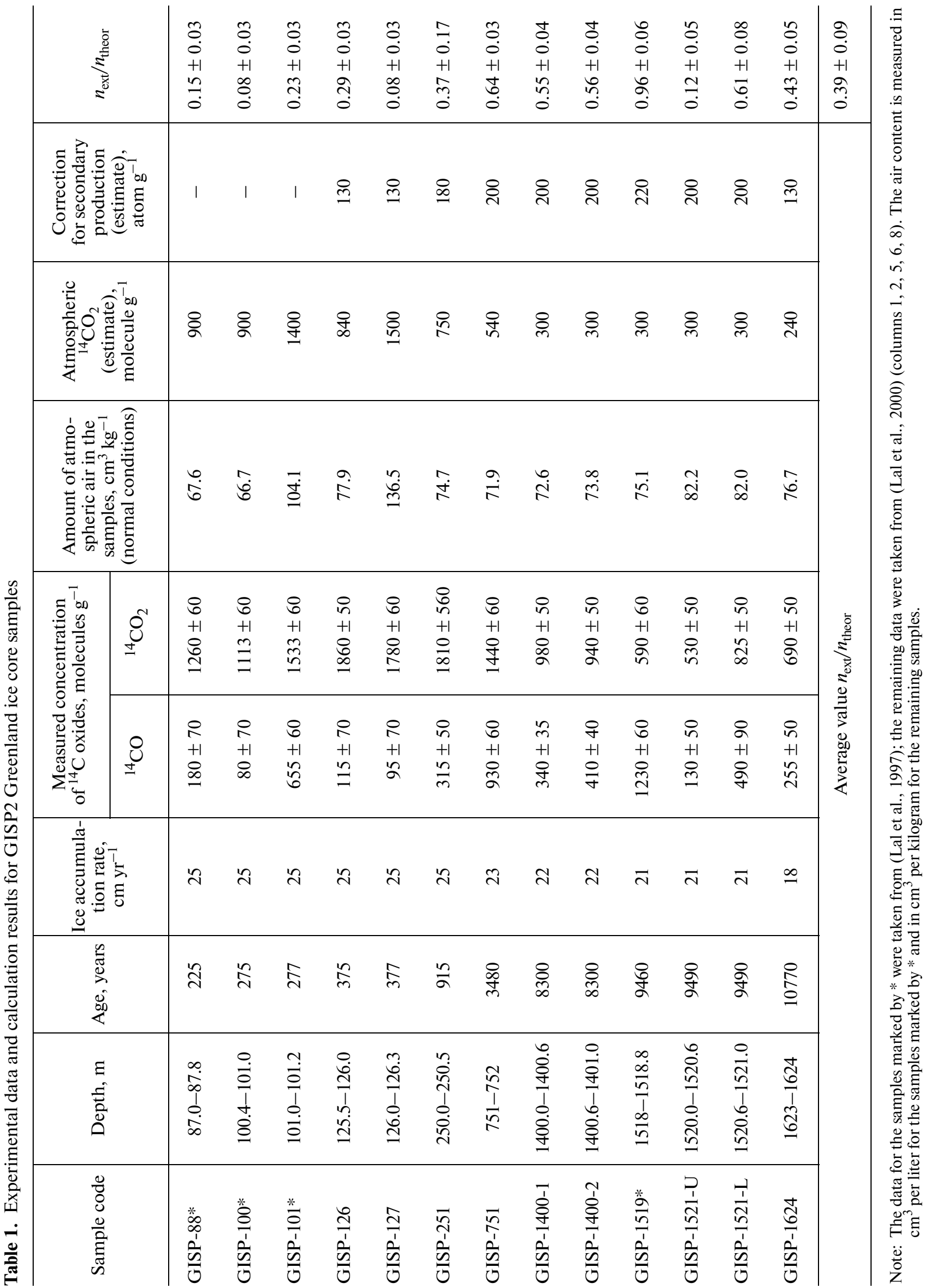


Table 2. Integral production rates of ${ }^{14} \mathrm{C}$ by cosmic ray components for the GISP2 station height and latitude $(Q$ values are given in $10^{3}$ atom $\mathrm{cm}^{-2} \mathrm{yr}^{-1}$ )

\begin{tabular}{c|c|c|c|c|c}
\hline Station & Height, km & $Q_{\mu f}$ & $Q_{\mu^{-}}$ & $Q_{h}$ & $Q_{\Sigma}$ \\
\hline GISP2 & 3.2 & $4.2 \pm 2.5$ & $9.3 \pm 1.9$ & $69 \pm 15$ & 83 \\
\hline
\end{tabular}

Note: $Q_{\mu f}, Q_{\mu}$, and $Q_{h}$ are the ${ }^{14} \mathrm{C}$ integral production rates during reactions caused by high-energy muons, during reactions of capture of slow negative muons, and during reactions caused by the cosmic ray nuclear-active component, respectively. The errors in the $Q_{\mu f}, Q_{\mu}-$ and $Q_{h}$ values are 60, 20, and 20\%, respectively (Heisinger et al., 2002a, 2002b; Jull et al., 1994). For comparison, the ${ }^{14} \mathrm{C}$ integral production rate in the atmosphere is 2 atom $\mathrm{cm}^{-2} \mathrm{~s}^{-1}$ or $6.3 \times 10^{7}$ atom $\mathrm{cm}^{-2} \mathrm{yr}^{-1}$ (Masarik and Beer, 1999).

are integral production rates of ${ }^{14} \mathrm{C}$ by the cosmic ray nuclear-active component, during reactions of capture of negative muons and reactions caused by highenergy muons, respectively; $Q=\int_{0}^{\infty} P(h) d h$, where $P(h)$ is the radionuclide production rate in ice at depth $h ; Q$ is measured in atom $\mathrm{cm}^{-2} \mathrm{yr}^{-1}$. When (1) was derived, it was assumed that $\frac{\lambda \Lambda}{s \rho} \ll 1(\Lambda$ is the characteristic depth of ${ }^{14} \mathrm{C}$ production). This condition is satisfied for the considered values of ice accumulation rates $(s)$. It is assumed that the entire ${ }^{14} \mathrm{C}$ is produced in the surface firn layer; i.e., the age of in situ produced ${ }^{14} \mathrm{C}$ coincides with the sample age.

The values of the radiocarbon production integral rates $\left(Q_{h}, Q_{\mu}\right.$, and $\left.Q_{\mu f}\right)$ for the GISP2 Greenland station height $(\sim 3.2 \mathrm{~km})$ are presented in Table 2 (see the calculation details in (Nesterenok and Naidenov, 2010)). The contribution of reactions caused by the cosmic ray nuclear-active component to the production of ${ }^{14} \mathrm{C}$ is about $85 \%$. Thus, radiocarbon is mostly produced in surface firn layers, the thickness of which does not exceed $10 \mathrm{~m}$, i.e., the penetration depth of the cosmic ray nuclear-active component.

An error indicated in Table 2 for the integral rate of radiocarbon production in reactions caused by the cosmic ray nuclear-active component $Q_{h}$ corresponds to an error of radiocarbon production in the surface layer of quartz that was obtained by Jull et al. (1994). An additional error of about $5-10 \%$ results from scaling this value for a given height and latitude (Desilets and Zreda, 2003). Also, according to the results of preliminary calculation, the attenuation length of the flux density of fast neutrons in ice may be much lower (by $30 \%$ ) than a corresponding value of $160 \mathrm{~g} \mathrm{~cm}^{-2}$ for quartz, which is used in this work and others (Nesterenok and Naidenov, 2010; Heisenger et al., 2002). This introduces an additional error into the value of $Q_{h}$.

Figure and column 9 of Table 1 present a ratio of the experimental data on ${ }^{14} \mathrm{C}$ produced in situ (corrected for atmospheric radiocarbon and production during storage) to the calculated concentration values $\left(n_{\text {exp }} / n_{\text {theor }}\right)$, where $n_{\text {theor }}$ was determined using expression (1). The indicated $n_{\text {exp }} / n_{\text {theor }}$ errors correspond to the errors of the experimental ${ }^{14} \mathrm{C}$ values without the $n_{\text {theor }}$ error. According to Figure, the ${ }^{14} \mathrm{C}$ in situ concentration only coincides with the calculated value for one of the considered ice samples; the experimental values do not exceed the theoretical ones for all remaining samples. The last column of Table 1 presents the average ratio value $\left\langle n_{\text {exp }} / n_{\text {theor }}\right\rangle=0.39 \pm 0.09(1 \sigma)$, which can be considered as a measure of the preservation degree of ${ }^{14} \mathrm{C}$ in firn typical of the Holocene.

\section{DIFFUSION OF ${ }^{14} \mathrm{CO}_{2}$ AND ${ }^{14} \mathrm{CO}$ IN FIRN}

As indicated above, in situ ${ }^{14} \mathrm{C}$ is mainly produced in surface firn layers. Any losses of ${ }^{14} \mathrm{C}$ by firn grains different from radioactive decay are possible during the ice formation stage up to the complete transformation of firn into ice. Let us assume that the escape rate of ${ }^{14} \mathrm{C}$ from firn grains is proportionate to the radiocarbon concentration in ice, i.e., $d n / d t=-\alpha n$. For simplicity, let us also assume that the coefficient $\alpha$ is constant during ice formation. In this approximation, for the ratio of the concentration of ${ }^{14} \mathrm{C}$ that is retained in firn grains during ice formation to that of ${ }^{14} \mathrm{C}$ that was produced initially, we have the following:

$$
n_{\text {pres }} / n_{\text {prod }}=e^{-\alpha t_{c}},
$$

where $t_{c}$ is the age of the ice at the firn-ice boundary. The presented model ignores the specific features of carbon oxide localization in firn grains and changes in firn properties during ice formation. The degree of ${ }^{14} \mathrm{C}$ preservation in firn grains $\left(\left\langle n_{\text {exp }} / n_{\text {theor }}\right\rangle \approx 0.4\right)$ was obtained for the considered Greenland ice samples. For the Greenland ice summit during the Holocene, the time of ice formation $\left(t_{c}\right)$ was about 200 years (Blunier et al., 1998). Consequently, according to (2), the characteristic time of carbon oxide preservation in firn at the Greenland ice summit during the Holocene is $t_{0}=1 / \alpha \approx 200$ years. 


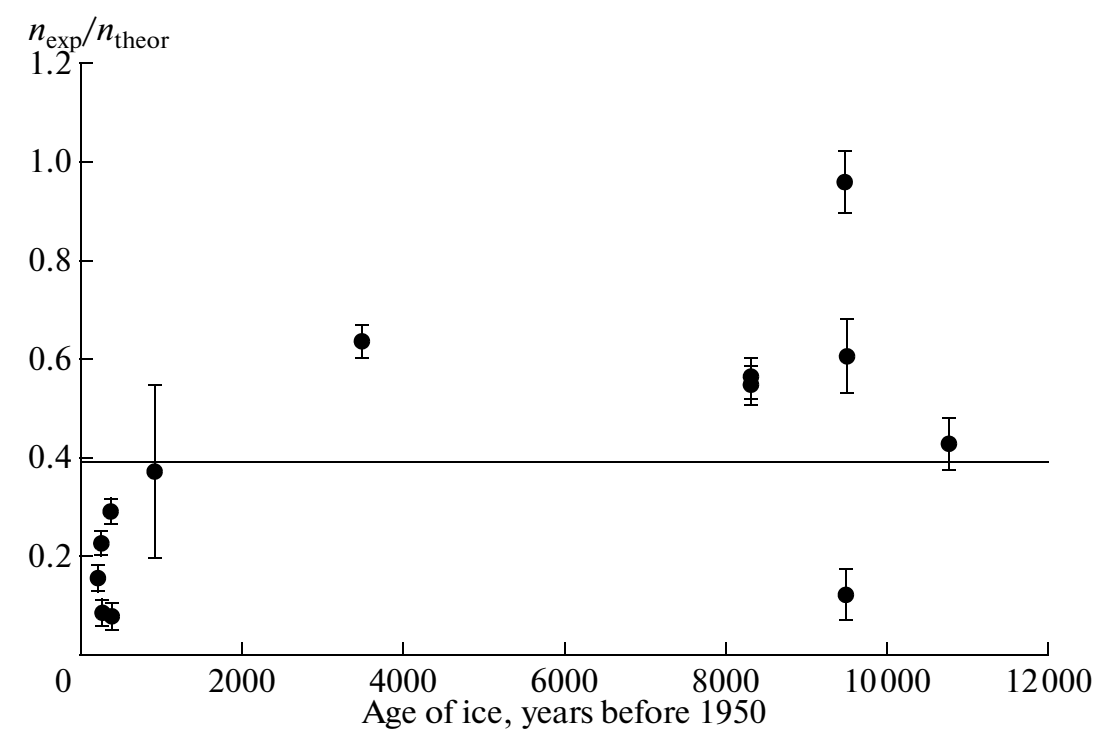

The ratio of the experimental data on the ${ }^{14} \mathrm{C}$ in situ concentration to the calculated values $\left(n_{\text {exp }} / n_{\text {theor }}\right)$ for the ice samples from the GISP2 Greenland core. The $n_{\text {theor }}$ values were determined using expression (1). A horizontal line shows the average value of the $n_{\text {exp }} / n_{\text {theor }}$ ratio: $\left\langle n_{\text {exp }} / n_{\text {theor }}\right\rangle=0.39 \pm 0.09(1 \sigma)$.

The coefficients of carbon oxide diffusion in ice are too small; therefore, it is impossible to determine these coefficients under laboratory conditions. However, these values can be determined indirectly. Ahn et al. (2008) presents the lower estimate for the $\mathrm{CO}_{2}$ diffusion coefficient in ice $\left(D_{\mathrm{CO}_{2}}>1.3 \times 10^{-13} \mathrm{~m}^{2} \mathrm{~s}^{-1}\right.$ for $\left.t=-23^{\circ} \mathrm{C}\right)$ obtained based on an analysis of the $\mathrm{CO}_{2}$ concentration profile in ice layers associated with melt layers. The value of the $\mathrm{CO}_{2}$ coefficient of diffusion computed in molecular dynamics simulation is larger than the estimate above by more than an order of magnitude and is $D_{\mathrm{CO}_{2}}=6 \times 10^{-11} \mathrm{~m}^{2} \mathrm{~s}^{-1}$ for the temperature at the top of the Greenland glacier $\left(t=-31^{\circ} \mathrm{C}\right)$ (Ikeda-Fukuzawa et al., 2004).

The characteristic escape time of ${ }^{14} \mathrm{CO}_{2}$ molecules produced within an ice grain with a radius $r$ toward the grain surface is:

$$
\tau_{\mathrm{CO}_{2}} \approx \frac{r^{2}}{D_{\mathrm{CO}_{2}}}<0.3 \cdot\left(\frac{r}{1 \mathrm{~mm}}\right)^{2} \text { years, }
$$

for $D_{\mathrm{CO}_{2}}>1.3 \times 10^{-13} \mathrm{~m}^{2} \mathrm{~s}^{-1}$. The size of ice grains in the upper firn layer vary from several tenths of a millimeter to several millimeters (Albert and Shultz, 2002). For $r \approx 1 \mathrm{~mm}$, the characteristic time of carbon dioxide diffusion within an ice grain $\left(\tau_{\mathrm{CO}_{2}}\right)$ is about a year. Molecules of $\mathrm{CO}$ are smaller than those of $\mathrm{CO}_{2}$; consequently, we can assume that the $\mathrm{CO}$ diffusion coefficient is larger and $\tau_{\mathrm{CO}}$ is smaller than $\tau_{\mathrm{CO}_{2}}$.

The time necessary for gas diffusion in air channels in surface firn layers is several days, and the total time required for gas diffusion from the firn bottom to its surface is about 6 years for central Greenland (Bender et al., 1997). Thus, the time required for gas diffusion within an ice grain and in firn air channels is much smaller than the lifetime of ${ }^{14} \mathrm{C}$ in the firn layer obtained at the beginning of this section. We could assume that some mechanisms are responsible for the preservation of ${ }^{14} \mathrm{C}$ in firn grains.

\section{HYDRATION OF ${ }^{14} \mathrm{CO}_{2}$ IN A DISORDERED ICE LAYER}

A crystal lattice becomes disordered in an ice crystal surface layer and at the boundary between ice monocrystals (Dash et al., 2006). The formation of a quasiliquid layer on an ice surface is experimentally observed for temperatures of about $200 \mathrm{~K}$ and higher. Quasiliquid layers, which form on firn grain surfaces and at the boundary between ice monocrystals, are considered to be a zone of localization of chemical compounds, where chemical reactions can proceed with these compounds (Grannas et al., 2007).

In experimental studies on $\mathrm{CO}_{2}$ adsorption on an ice surface, the amount of adsorbed carbon dioxide increased with an increasing temperature ("anomalous" adsorption); this is assumed to be related to the appearance and thickening of a quasiliquid layer on the ice surface (Ocampo and Klinger, 1982). The hydration of $\mathrm{CO}_{2}$ most probably takes place in disordered ice layers, similarly to the hydration of $\mathrm{CO}_{2}$ in water solutions (Johnson, 1982):

$$
\begin{gathered}
\mathrm{CO}_{2}+\mathrm{H}_{2} \mathrm{O} \leftrightarrow \mathrm{HCO}_{3}^{-}+\mathrm{H}^{+} \\
\leftrightarrow \mathrm{H}_{2} \mathrm{CO}_{3} \leftrightarrow \mathrm{CO}_{2}+\mathrm{H}_{2} \mathrm{O} .
\end{gathered}
$$

Assonov et al. (2005) studied the ${ }^{18} \mathrm{O}$ isotope exchange rate between the firn air $\mathrm{CO}_{2}$ component and 
ice. The processes of hydration and dehydration of $\mathrm{CO}_{2}$ molecules on a firn grain surface were considered. For the isotope exchange rate, it was found that $k \propto e^{-\Delta E / R T}$, where $T$ is the firn temperature, and $\Delta E=7.8 \pm$ $0.8 \mathrm{kcal} \mathrm{mol}^{-1}$. For the temperature at the Greenland ice summit $\left(-31^{\circ} \mathrm{C}\right)$, the characteristic isotope exchange time would be about 50 years, according to (Assonov et al., 2005) (the time during which the difference between the content of an ${ }^{18} \mathrm{O}$ isotope in $\mathrm{CO}_{2}$ gas and the equilibrium value of this content decreases by a factor of $e$ ). This timescale is comparable with the characteristic time of the ${ }^{14} \mathrm{C}$ loss by firn grains ( 200 years) in the order of magnitude. This can result from the fact that common mechanisms form the basis of the aformentioned processes; i.e., the hydration of carbon dioxide molecules in a disordered ice layer in (on) firn grains can be one of the causes of the relatively high ${ }^{14} \mathrm{CO}_{2}$ preservation degree in firn grains.

The adsorption of $\mathrm{CO}$ on an ice surface under the conditions of low temperatures (about $100 \mathrm{~K}$ and lower) was studied experimentally and using the molecular dynamics calculations (Manca et al., 2001). It was discovered that carbon monoxide bond energy on an ice surface is about $2.5 \mathrm{kcal} \mathrm{mol}^{-1}$. Any data on $\mathrm{CO}$ adsorption or solubility in a quasiliquid ice layer are absent. Nevertheless, we can assume that lowenergy bonds between ${ }^{14} \mathrm{CO}$ and $\mathrm{H}_{2} \mathrm{O}$ with energy of about $2.5 \mathrm{kcal} \mathrm{mol}^{-1}$ form in this case.

\section{DISCUSSION}

The parameters responsible for the ${ }^{14} \mathrm{C}$ concentration level in the ice samples can be divided into two groups: parameters controlling radiocarbon production in ice and parameters responsible for the degree of carbon oxide preservation in firn grains.

The degree of radiocarbon production in ice depends on cosmic ray intensity. The cosmic ray intensity near a glacier surface depends on the following two factors: 1) the intensity of primary cosmic rays in the upper atmosphere, i.e., on the solar activity level and the geomagnetic field value; 2) the thickness of the atmosphere over the glacier, i.e., on the atmospheric pressure and glacier height above sea level. Lal et al. (2005) quantitatively analyzed the effect of the listed factors on the ${ }^{14} \mathrm{C}$ in situ production rate. For latitudes of $\lambda>60^{\circ}$, the geomagnetic cutoff rigidity is not more than 2 GV (Masarik and Beer, 1999; Desilets and Zreda, 2003). In this case, the effect of magnetic variations on the production rate of cosmogenic nuclides is insignificant. The level of solar activity is the main parameter responsible for the cosmic ray intensity near the glacier surface and, consequently, for the radionuclide production rate.

Climatic conditions belong to parameters responsible for the degree of ${ }^{14} \mathrm{C}$ preservation in firn grains. The age of the considered ice samples is not more than
11000 years, i.e., the beginning of the Holocene, which is generally characterized by rather stable climatic conditions (Dergachev et al., 2006). Seasonal or other short-term variations in climatic conditions can substantially affect the physicochemical properties of the snow cover; however, these variations are local in depth. Variations in the influencing parameters can affect the experimental value of the ${ }^{14} \mathrm{C}$ concentration, when the period of these variations is larger than the characteristic time of ${ }^{14} \mathrm{C}$ production and the timescale of averaging the ${ }^{14} \mathrm{C}$ concentration related to the finite dimensions of an ice sample. For the considered samples from the GISP2 ice core, this time is about 25 years (Lal et al., 2005).

The processes of liberation of chemicals adsorbed or dissolved in ice are closely related to the processes of firn grain metamorphism. Sublimation or evaporation of some ice grains and vapor condensation on other grains result in a change in the grain size and shape and, consequently, in the firn physical properties. The process of firn grain metamorphism almost always results in a decrease in a specific area of snow and firn surface, inevitably resulting in a decrease in the number of chemicals adsorbed on the ice grain surface (Grannas et al., 2007). Thus, we can anticipate that the experimental values of the ${ }^{14} \mathrm{C}$ concentration in ice samples will be systematically smaller than the theoretical values.

Delmas et al (2004) analyzed ${ }^{36} \mathrm{Cl}$ cosmogenic nuclide concentration in snow samples taken at the Vostok Antarctic station. A considerable spread of ${ }^{36} \mathrm{Cl}$ bomb peak was found. Thus, the ${ }^{36} \mathrm{Cl}$ redistribution in the firn layer is caused by the intensity of the snow grain recrystallization and sublimation under these climatic conditions. It was indicated above that the adsorption of $\mathrm{CO}_{2}$ on the ice surface is dissociative as in the case of $\mathrm{HCl}$. For the Taylor Dome and Vostok Antarctic stations, the experimentally measured ${ }^{14} \mathrm{C}$ values are much smaller than the calculated values (Lal et al., 2001). In addition, it was indicated that the ${ }^{14} \mathrm{C}$ concentration in the ice samples from the Antarctic ice cores is largely related to the radiocarbon production by the cosmic ray muon component at great depths (Nesterenok and Naidenov, 2010). This indicates that the degree of ${ }^{14} \mathrm{C}$ in situ preservation in the firn layer is extremely low. A different degree of retention of ${ }^{36} \mathrm{Cl},{ }^{14} \mathrm{CO}_{2}$, and ${ }^{14} \mathrm{CO}$ carbon oxides by firn grains is explained by the considerable difference in the chemical properties of these compounds.

\section{CONCLUSIONS}

We indicated that the experimental values of the ${ }^{14} \mathrm{C}$ concentration for the samples from the GISP2 Greenland ice core are systematically smaller than the calculated values. A deficit in in situ ${ }^{14} \mathrm{C}$ is the general characteristics of the ice samples from the Greenland 
and Antarctic stations. The hydration of ${ }^{14} \mathrm{CO}_{2}$ in a disordered ice layer, which is formed on the firn grain surface and at the boundary between ice monocrystals, is considered among the main processes responsible for the ${ }^{14} \mathrm{C}$ concentration. Low-energy bonds between ${ }^{14} \mathrm{CO}$ molecules and free hydroxyl groups of water can be formed in the case of ${ }^{14} \mathrm{CO}$.

\section{ACKNOWLEDGMENTS}

We thank Cand. Sc. (Chem.) B. M. Lyuminarskii and V. P. Semenov for valuable pieces of advice and remarks, D. Lal and collaborators for the opportunity of using data from their publications, and the reviewer for substantial comments and remarks.

\section{REFERENCES}

Ahn, J., Headly, M., Wahlen, M., Brook, E.J., Mayewski, P.A., and Taylor, K.C., $\mathrm{CO}_{2}$ Diffusion in Polar Ice: Observations from Naturally Formed $\mathrm{CO}_{2}$ Spikes in the Siple Dome (Antarctica) Ice Core, J. Glaciol., 2008, vol. 54, no. 187 , pp. $685-695$.

Albert, M.R. and Shultz, E.F., Snow and Firn Properties and Air-Snow Transport Processes at Summit, Greenland, Atmos. Environ., 2002, vol. 36, pp. 2789-2797.

Alley, R.B., The Younger Dryas Cold Interval as Viewed from Central Greenland, Quat. Sci. Rev., 2000, vol. 19, pp. 213-226.

Assonov, S.S., Brenninkmeijer, C.A.M., and Jöckel, P., The ${ }^{18} \mathrm{O}$ Isotope Exchange Rate between Firn Air $\mathrm{CO}_{2}$ and the Firn Matrix at Three Antarctic Sites, J. Geophys. Res., 2005, vol. 110D, pp. 18310-18323.

Bender, M., Sowers, T., and Brook, E., Gases in Ice Cores, Proc. Nat. Acad. Sci. USA, 1997, vol. 94, pp. 83438349.

Blunier, T., Chappellaz, J., Schwander, J., Dallenbach, A., Stauffer, B., Stocker, T.F., Raynaud, D., Jouzel, J., Clausen, H.B., Hammer, C.U., and Johnsen, S.J., Asynchrony of Antarctic and Greenland Climate Change during the Last Glacial Period, Nature, 1998, vol. 394, pp. 739-743.

Dash, J.G., Rempel, A.W., and Wettlaufer, J.S., The Physics of Premelted Ice and Its Geophysical Consequences, Rev. Mod. Phys., 2006, vol. 78, pp. 695-741.

Delmas, R.J., Beer, J., Synal, H.-A., Muscheler, R., Petit, J.-R., and Pourchet, M., Bomb-Test ${ }^{36} \mathrm{Cl}$ Measurements in Vostok Snow (Antarctica) and the Use of ${ }^{36} \mathrm{Cl}$ as a Dating Tool for Deep Ice Cores, Tellus, 2004, vol. 56, pp. 492-498.

Dergachev, V.A., Dmitriev, P.B., Raspopov, O.M., and Jungner, H., Cosmic Ray Flux Variations, Modulated by the Solar and Earth's Magnetic Fields, and Climate Changes. 1. Time Interval from the Present to 10-12 ka Ago (the Holocene Epoch), Geomagn. Aeron., 2006, vol. 46, no. 1, pp. 123-134 [Geomagn. Aeron. (Engl. Transl.), 2006, vol. 46, pp. 118-128].

Desilets, D. and Zreda, M., Spatial and Temporal Distribution of Secondary Cosmic-Ray Nucleon Intensities and Applications to in situ Cosmogenic Dating, Earth Planet. Sci. Lett., 2003, vol. 206, pp. 21-42.
Grannas, A.M. and 34 Co-Authors, An Overview of Snow Photochemistry: Evidence, Mechanisms and Impacts, Atmos. Chem. Phys., 2007, vol. 7, pp. 4329-4373.

Heisinger, B., Lal, D., Jull, A.J.T., Kubik, P., Ivy-Ochs, S., Neumaier, S., Knie, K., Lazarev, V., and Nolte, E., Production of Selected Cosmogenic Radionuclides by Muons. 1. Fast Muons, Earth Planet. Sci. Lett., 2002a, vol. 200, pp. 345-355.

Heisinger, B., Lal, D., Jull, A.J.T., Kubik, P., Ivy-Ochs, S., Knie, K., and Nolte, E., Production of Selected Cosmogenic Radionuclides by Muons. 2. Capture of Negative Muons, Earth Planet. Sci. Lett., 2002b, vol. 200, pp. 357-369.

Ikeda-Fukuzawa, T., Kawamura, K., and Hondoh, T., Mechanism of Molecular Diffusion in Ice Crystals, Mol. Simul., 2004, vol. 30, pp. 973-979.

Johnson, K.S., Carbon Dioxide Hydration and Dehydration Kinetics in Seawater, Limnol. Oceanogr., 1982, vol. 27, pp. 849-855.

Jull, A.J.T., Lifton, N., Phillips, W.M., and Quade, J., Studies of the Production Rate of Cosmic-Ray Produced ${ }^{14} \mathrm{C}$ in Rock Surfaces, Nuclear Instrum. Meth. Phys. Res., 1994, vol. 92, pp. 308-310.

Lal, D., Jull, A.J.T., Burr, G.S., and Donahue, D.J., Measurements of in situ ${ }^{14} \mathrm{C}$ Concentrations in Greenland Ice Sheet Project 2 Ice Covering a 17 kyr Time Span: Implications to Ice Flow Dynamics, J. Geophys. Res., 1997, vol. 102C, pp. 26505-26510.

Lal, D., Jull, A.J.T., Burr, G.S., and Donahue, D.J., On the Characteristics of Cosmogenic in situ ${ }^{14} \mathrm{C}$ in Some GISP2 Holocene and Late Glacial Ice Samples, Nuclear Instrum. Meth. Phys. Res., 2000, vol. 172, pp. 623-631.

Lal, D., Jull, A.J.T., Donahue, D.J., Burr, G.S., Deck, B., Jouzel, J., and Steig, E., The Record of Cosmogenic in situ Produced ${ }^{14} \mathrm{C}$ in Vostok and Taylor Dome Ice Samples: Implications for Strong Role of Wind Ventilation Processes, J. Geophys. Res., 2001, vol. 106D, pp. 31933-31941.

Lal, D., Jull, A.J.T., Pollard, D., and Vacher, L., Evidence for Large Century Time-Scale Changes in Solar Activity in the Past $32 \mathrm{kyr}$, Based on in situ Cosmogenic ${ }^{14} \mathrm{C}$ in Ice at Summit, Greenland, Earth Planet. Sci. Lett., 2005, vol. 234, pp. 335-349.

Manca, C., Martin, C., Allouche, A., and Roubin, P., Experimental and Theoretical Reinvestigation of $\mathrm{CO}$ Adsorption on Amorphous Ice, J. Phys. Chem., 2001, vol. 105, pp. 12861-12869.

Marley, N.A., Gaffney, J.S., Tackett, M.J., Sturchio, N.C., Heraty, L., Martinez, N., Hardy, K.D., Machany-Rivera, A., Guilderson, T., MacMillan, A., and Steelman, K., The Impact of Biogenic Carbon Sources on Aerosol Absorption in Mexico City, Atmos. Chem. Phys., 2009, vol. 9, pp. 1537-1549.

Masarik, J. and Beer, J., Simulation of Particle Fluxes and Cosmogenic Nuclide Production in the Earth's Atmosphere, J. Geophys. Res., 1999, vol. 104D, pp. 1209912111.

Masarik, J. and Reedy, R.C., Terrestrial CosmogenicNuclide Production Systematics Calculated from Numerical Simulations, Earth Planet. Sci. Lett., 1995, vol. 136, pp. 381-395. 
McCracken, K.G., Beer, J., and McDonald, F.B., The Long-Term Variability of the Cosmic Radiation Intensity at Earth as Recorded by the Cosmogenic Nuclides, in The Solar System and beyond: Ten Years of ISSI, Geiss, J. and Hultqvist, B., Eds., Bern: Int. Space Sci. Inst., 2005.

Meese, D.A., Gow, A.J., Grootes, P.M., Mayewski, P.A., Ram, M., Stuiver, M., Taylor, K.C., Waddington, E.D., and Zielinski, G.A., The Accumulation Record from the GISP2 Core as an Indicator of Climate Change throughout the Holocene, Science, 1994, vol. 266, pp. 1680-1682.

Nesterenok, A.V. and Naidenov, V.O., Radiocarbon in the Antarctic Ice: The Formation of the Cosmic Ray Muon Component at Large Depths, Geomagn. Aeron., 2010, vol. 50, no. 1, pp. 138-144 [Geomagn. Aeron. (Engl. Transl.), 2010, vol. 50, p. 134].

Ocampo, J. and Klinger, J., Adsorption of $\mathrm{N}_{2}$ and $\mathrm{CO}_{2}$ on Ice, J. Colloid. Interface Sci., 1982, vol. 86, no. 2, pp. $377-383$.
Petit, J.R., Jouzel, J., Raynaud, D., Barkov, N.I., Barnola, J.-M., Basile, I., Bender, M., Chappellaz, J., Davis, M., Delaygue, G., Delmotte, M., Kotlyakov, V.M., Legrand, M., Lipenkov, V.I., Lorius, C., Pepin, L., Ritz, C., Saltzman, E., and Stievenard, M., Climate and Atmospheric History of the Past 420000 Years from the Vostok Ice Core, Antarctica, Nature, 1999, vol. 399, pp. 429-436.

Roessler, K., Suprathermal Chemistry in Space, Proc. Int. School of Physics "Enrico Fermi", 111, Solid-State Astrophysics, Bussoletti and Strazzulla, Eds., Varenna, 1991, pp. 197-266.

Smith, A.M., Levchenko, V.A., Etheridge, D.M., Lowe, D.C., Hua, Q., Trudinger, C.M., Zoppi, U., and Elcheikh, A., In Search of in-situ Radiocarbon in Low Dome Ice and Firn, Nuclear Instrum. Meth. Phys. Res. B, 2000, vol. 172, pp. 610-622.

Van der Kemp, W.J.M., Alderliesten, C., Van der Borg, K., De Jong, A.F.M., Lamers, R.A.N., Oerlemans, J., Thomassen, M., and Van de Wal, R.S.W., In situ Produced ${ }^{14} \mathrm{C}$ by Cosmic Ray Muons in Ablating Antarctic Ice, Tellus, 2002, vol. 54, no. 2, pp. 186-192. 